\title{
DISCUSSION
}

\section{Further investigations at the Folkestone Warren landslide}

\author{
N. A. TRENTER and C. D. WARREN (1996). Géotechnique 46, No. 4, 589-620
}

\section{A. M. Muir Wood}

This account reviews many aspects of the Folkestone Warren landslips. However, as stated by Muir Wood (1994) 'there can never be a conclusive termination of the historical analysis of events' at this site. Particular issues that merit further consideration include the following.

Muir Wood (1994) examined the extension factor $\beta$ for the Gault from evidence of the 1948 series of boreholes along two sections roughly corresponding to the authors' sections $1-1$ and midway between sections $1-1$ and $2-2$ respectively. $\beta$ is defined as $h_{0} / h$, where $h_{0}$ and $h$ represent original and slipped thickness respectively. $\beta \sim 3$ apart from the Upper Gault inland from the 'toe' slips, for which $\beta \sim 6$. This would imply reduced extension of the Upper Gault affected by the 'toe slips', which seems improbably, necessitating reverse movement of intermediate slips, such as indicated at Slip 2 in Fig. 8. It now seems that the 1948 boreholes were unrepresentative in this respect; that generally the dip of the slipped strata is steeper (to be expected from geometrical analysis; Muir Wood, 1994) than indicated on Fig. 8, with, for example, at least one additional slip intermediately between boreholes $48 / 17$ and 82/16, thus increasing $h$ and eliminating this reverse movement along Slip 2. For $\beta=3$ and a rotation $30^{\circ}$, the horizontal interval between successive 'type 1' slips would be about $20 \mathrm{~m}$ (Muir Wood, 1994).

There appears to be much merit in analysing a landslide of such highly non-circular nature by a system of blocks that more nearly represent the form of the failure. Thus Slip 1 (Fig. 9, section 2-2) may be neatly subdivided (as illustrated diagrammatically by Figure 14) into:

(a) an active sliding block, A

(b) a rotating block, $\mathrm{B}$

(c) a passive sliding block, C, including allowance for toe action

A conventional block analysis would then assume that the resultant normal reaction, $R_{\mathrm{AB}}$, and between $\mathrm{A}$ and $\mathrm{B}$ and the normal reaction, $R_{\mathrm{BC}}$, between $\mathrm{B}$ and $\mathrm{C}$ each acted at about two-thirds depth (i.e. $0.67 d$ ) along the respective interfaces. In this manner, making reasonable allowance for the loading towards the sea caused by water percolating through the slipped mass but otherwise adopting the authors' assumptions, limiting equilibrium would determine, for the Gault, $\phi_{\mathrm{r}}^{\prime} \sim 10 \cdot 2^{\circ}$. Kinematically, however, as with the method of slices used by the authors, there remains the need to take account of complex shearing of 'virgin' material-that is, material at well above residual strength-at the block interfaces for movement to occur. A block analysis at least presents opportunity to explore the significance of this feature.

Translation of A coupled with the combined translation and rotation of $\mathrm{B}$ causes complex compressional shearing along the upper part of interface $\mathrm{AB}$, and extensional shearing along the lower part: that is, towards the slip surface. Probably the most important effect is that of shifting upwards the line of the resultant normal reaction, $R_{\mathrm{AB}}$, from $0.67 d$ to, say, $0.5 d$. At interface $\mathrm{BC}$, the complementary effect causes a lowering of the resultant normal reaction, $R_{\mathrm{BC}}$, from $0.67 d$ to, say, $0.8 d$. The consequence is that of reducing the mechanical advantage of the driving forces. The radius of the slip surface for block B is about $100 \mathrm{~m}$, and the consequence of the above reasoning varies the lever arm of $R_{\mathrm{AB}}$ from, say, $74 \mathrm{~m}$ to $67.5 \mathrm{~m}$ and that of $R_{\mathrm{BC}}$ from $78 \mathrm{~m}$ to $84 \mathrm{~m}$. Maintaining all other assumptions unchanged, $\phi_{\mathrm{r}}^{\prime} \sim 8.6^{\circ}$ - that is, a reduction of $106^{\circ}$ - suggesting that the kinematics of this form of non-circular slip should not be glossed over. A fuller analysis of the interface deformations would probably indicate that this simple device overestimates the effect, but by no great margin, for 'virgin' chalk.

The explanation of the toe ridges as representing undercutting of old slip surfaces inclined steeply seaward could be fully compatible with the extrusion phenomenon described by Casey (1955) as preceding major slipping, since a small forward movement of the slipping material, prior to major movement, could be associated with the observed extrusion of remoulded material from the interface. In 1948, there was surface exposure of a band of such remoulded Gault up to $1 \mathrm{~m}$ wide with a step to seawards (Muir Wood, 1955a; Figs 14 and 15).

\section{J. N. Hutchinson, Imperial College, and E. N. Bromhead,} University of Kingston

After our investigations of the Warren in the late 1970s (Hutchinson et al. 1980), we communicated to British Railways (Southern Region) our belief that falls from the High Cliff, particularly in its western parts, constituted the greatest potential hazard to the railway through the Warren. However, the authors' paper, which springs out of the additional investigations that followed in 1982-83, does not deal with this matter. We hope that it will be covered by the further report mentioned on $\mathrm{p}$. 596.

In view of the well-known great variability of liquid limit, clay fraction and angle of drained residual shear strength throughout the Gault (Fig. 7), it is inappropriate in Figs 4 and 5 to plot all the points, undifferentiated as to index properties, as if representing one material. (Some index properties are given in Table 2, but they are not readily related to the points on Figs 4 and 5.) Furthermore, Fig. 7 indicates that the liquid limit of the Gault at the Warren ranges from about $41 \%$ to $117 \%$, whereas the minimum and maximum liquid limits of the samples tested in shear are, according to Table 3, 50\% and $83 \%$ respectively. Thus any 'average' values of shear parameters obtained from the present Figs 4 and 5 are unlikely to be representative.

One of the interesting factors revealed by the paper is the way in which the three en echelon, more seaward slips ('Slips 2 ') tend to hinge about their shallower, western ends. This conclusion seems well supported by the observations, but the further argument that, as a result, first-time, near-peak shearing is taking place in the hinge areas while elsewhere in Slips 2 residual strengths apply, is unconvincing. This may have been the case during the initiation of these slips, but by now, in their greatly displaced state noted on p. 607, the strengths on all their slip surfaces are likely to aprroximate to the residual. The difference between the back-calculated and laboratory determi-

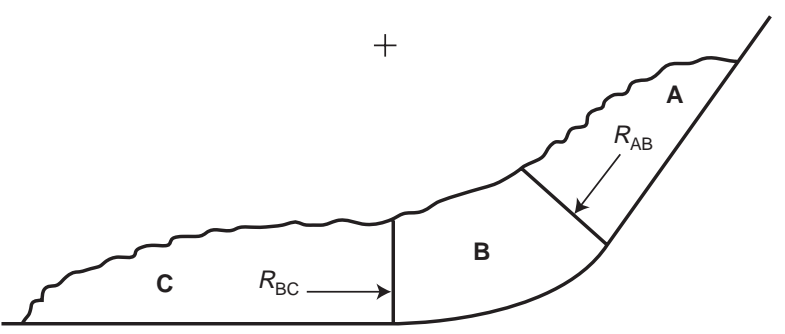

Fig. 14. Diagram of three-block stability analysis 
nations of shear strength at Horsehead Point are more likely to be concerned with factors such as the incompletely explored variability of shear parameters throughout the Gault, the neglect of three-dimensional analyses, uncertainties about the groundwater pressures obtaining, and the conditions on the rather complicated contracts across the Slip 2 failure surface, especially with the adjoining slice to landward (Fig. 10).

No reference is made to the findings of Hutchinson (1995) that the basal slip surfaces in the five only landslides (Castle Hill to Danton Pinch) affecting the Chalk/Gault scarp immediately to the west of the Warren are all seated in common, slipprone zone within Bed XI of the Gault. It would be interesting to know whether any movements have been observed on this horizon anywhere in the Warren complex.

In the previous investigations of Hutchinson (1969) and Hutchinson et al. (1980), no resources were available for borings or instrumentation, and, for the back-analyses, rather wide assumptions had to be made regarding the maximum and minimum groundwater pressures obtaining on the slip surfaces at failure. It is thus disappointing that, despite being able to carry out an extensive subsurface investigation, the present authors were unable to improve significantly on the earlier state of knowledge on this important matter.

One of us (JNH) has observed and sampled putty chalk within the debris of old chalk flows on the shore platform beneath Abbotscliff, jsut west of the Warren, and used this occurrence to support the inference of a mechanism of excess pore water pressure generation by 'impact collapse' in the chalk falls leading to these flows (Hutchinson, in press). It was thus particularly interesting to see the authors' reports of great thicknesses of broken chalk debris and putty chalk on the Warren Undercliff in an area known to be prone to large chalk flows.

Minor points include: the units of lateral movement need to be added to Fig. 3; at the foot of p. 595, Table 2 should be Table 3; values of normal effective stresses used in the shear tests could, with advantage, be added to Table 2; a fuller treatment of the Late-glacial/Holocene pattern of landslide activity (pp. 613-614) is given by Hutchinson (1987); the reference on 'Landslide hazard assessment', quoted as 'in press' was published in 1995 and is given in full below.

\section{R. A. Milbourne}

During the course of research on the Gault Clay (Cretaceous, Middle and Upper Albian) carried out mainly at PRIS, University of Reading, throughout 1984-90, the writer discussed Gault matters with Colin Warren, joint author of the paper under discussion. It emerged that the core from Borehole 82/10 was housed in the Civil Engineering Department of Kingston Polytechnic (now University). Contact was made with Professor E. Bromhead of that Department, and permission to study and sample the core was granted. The Upper Gault portion of the core is complete and unaffected by either the rotational faulting or landslipping described by the authors, and this is in accordance with their Fig. 8 (p. 600). The Lower Gault portion is different, exhibiting extensive fracturing with slickenside surfaces, macrofossil and bedding distortion, intermittent liquefaction with consequent breaks in the stratigraphical sequence, and the formation of late diagnostic mineral phases resulting from contact with oxygenated groundwater. These features appear to be at variance with Fig. 8, and show that the Lower Gault has suffered disturbance beneath undisturbed Upper Gault and Chalk to the north of Slip 1. This indicates an early stage in the formation of another listric fault in the High Cliff erosion sequence. The surface expression of this fault would be ground cracking parallel to the cliff edge, a feature commonly found along coastlines where competent rocks overlie wet Mudstones.

The core illustrates well the manner in which the Lower Gault clays become fractured and pulverised during slipping. The resulting fracture porosity allows the ingress of both surface and groundwater with consequent collapse and liquefaction of the clay, features observable surficially throught the Warren and which appear to be responsible for much of its morphology.
Porosity and permeability characteristics are of major importance in the behaviour of the mobile Gault. The formation is generally regarded as impermeable, but there are horizons within it that have positive poroperm characteristics. The most important of these is the 'Greensand Seam', which, when saturated, facilitates the slipping of the wet basel Gault over the indurated top of the Folkestone Beds.

The undisturbed nature of Upper Gault Beds XI, XII and XIII in the core has enabled accurate measurements and observations to be made on unweathered strata that are not exposed in unbroken sequence at outcrop. This has been of immense help to the writer in the serach for a detailed chemical/ mineralogical stratigraphy for the Gault, and useful comparisons between 82/10 and cores from Channel Tunnel boreholes have also been made.

From the foregoing it will be apparent that the $82 / 10$ core is an important one. Colin Warren and Eddie Bromhead were prevailed upon to allow its transfer to the Core Store of the British Geological Survey at Keyworth, where it is now preserved. The core has suffered a little from sampling, small quantities of material having been removed for chemical analysis by the writer and for micropalaeontological analysis by $\mathrm{Dr}$ Jill Eyers of the Open University and Elizabeth Erba of Naples. What remains is excellent material available to all research workers, a fitting sequel to an excellent piece of research by the authors and a tribute to the generous facilities afforded the writer by Eddie Bromhead and his colleague Roger Curtis at Kingston.

\section{P. M. James, Consulting Geotechnical Engineer}

During research in slopes at Imperial College in the late 1960s, I analysed a number of the Hutchinson (1969) sections using the Morgenstern \& Price method. One section, W4, gave a required $\phi_{\mathrm{r}}=8^{\circ}$ for $c^{\prime}=0$, which was substantially lower than the required strength for the other sections along the Warren. I no longer have the analysis but did record that this particular section contained virtually no chalk/chalk rubble along its slip plane. My thoughts on this anomaly were, at the time (James, 1970):

(a) Residual strengths would develop much more quickly along bedding in the Gault than across bedding in the chalk/chalk rubble. Hence the use of residual strengths in the chalk might well underestimated its contribution to stability. In turn, this would cause the analyses to overestimate the strength required in the Gault: that is, a higher required $\phi_{\mathrm{r}}$ for the Gault would be estimated.

(b) More likely, it was considered that some beds in the Gault contained higher percentages of montmorillonite than the average and hence could have a lower intrinsic residual strength than previously recorded at the time.

The latter explanation appears to be given a degree of confirmation from the mass of results produced by the authors.

\section{Authors' reply}

To A. M. Muir Wood

Sir Alan Muir Wood makes three points, which are discussed in turn below.

Analysis of the 1948 borehole information in the neighbourhood of section 1-1 does indeed suggest a reduced extension of the Upper Gault affecting Slip 2, as compared with the intermediate slips between Slip 1 and Slip 2. This finding could be considered anomalous in respect of the information produced by the other boreholes sited further east, where the more normal situation of increased extension and rotation exists, moving seawards from the High Cliff. A possible explanation, as intimated by Sir Alan, could be that the dip of the strata is steeper than indicated on the section, and that there are additional intermediate slips between boreholes 48/17 and 82/16. An alternative explanation, preferred by the authors, is that the initial movements in this area of the Warren were so mobile that the complete Chalk and Gault sequence became detached 
from the original cliff face, with chalk rubble filling the void created landward, as noted on p. 603 of the authors' paper.

Sir Alan analyses the authors' section 2-2 (Figure 9) by a system of blocks, and a calculated residual $\phi_{\mathrm{r}}^{\prime}$ of $10 \cdot 2^{\circ}$ is obtained for the Gault for the authors' Slip 1. No precise details are given of the pore-pressure conditions assumed, so the authors are unable to compare this result directly with their own for this section. By changing the positions of the lines of action of the resultant normal forces between the blocks, as movement is postulated to occur, Sir Alan finds that the calculated $\phi_{\mathrm{r}}^{\prime}$ reduces to $8.6^{\circ}$, or a reduction in the effective shear strength along the failure surface of $1 \cdot 6^{\circ}$. Assumptions had to be made as to the size of the changes of the lines of action of the resultant normal forces between the blocks. It is not known if or how the inter-slice shear forces were handled. Consequently, it is not clear to the authors whether the reduction in calculated $\phi_{\mathrm{r}}^{\prime}$ is realistic or not.

The authors agree with Sir Alan on the value of the observations of Casey (1955), which seem to have been needlessly neglected in some of the publications in recent years. If, as is obvious from the borehole evidence, very large sections of the Gault have been cut out by landslide activity during the formation of the Slip 2 features at Warren Halt and Horsehead Point, the question has to be asked: where has this volume of material been displaced to? The obvious answer is seawards to be eroded and washed away. Casey's observation that 'Masses of Gault had been squeezed up through the sand almost like toothpaste out of a tube...' is a particularly direct and vivid description of one important part of the process. It also accords with the authors' observations (p. 614) that the material found on the Slip 2 failure plane was disturbed, softened and remoulded: that is fully in accord with the 'toothpaste' consistency observed by Casey.

\section{To J. N. Hutchinson and E. N. Bromhead}

Professor Hutchinson and Professor Bromhead make several comments on the paper, which are dealt with in the order in which they were raised:

Contrary to the statement made by Hutchinson and Bromhead, the authors discussed falls from the High Cliff on pp. $603,607,614$ and 619 of their paper; the contribution of these rock falls to landslide activity is decribed.

Hutchinson and Bromhead make detailed criticisms of the presentation of the geotechnical properties in the paper and their range of validity:

(a) It would have been impossible to present the shear strength data illustrated in Figs 4 and 5, together with their corresponding index properties, at the scale selected; at least a full page would have had to be dedicated to each figure to avoid congestion, which was quite impracticable given the pressure on space.

(b) Regarding the range of validity of the index property data of the Gault, those of the authors fall within the scatter produced by Muir Wood (1955a) and Hutchinson (1969), except for Gault Bed XIII, where Muir Wood's liquid limit data are usually higher. This is no surprise, because the authors found that the Gault at this horizon was frequently silty and consequently a relatively low liquid limit would be expected. At Castle Hill, samples of Gault taken at $1 \mathrm{~m}$ intervals throughout its full thickness produced liquid limits for the Upper Gault ranging from $60 \%$ to $83 \%$, apart from one glauconitic sample that yielded $43 \%$ (Mott Hay \& Anderson on the Channel Tunnel project, 1987). These results support those of the authors.

(c) The range of $\phi_{\mathrm{r}}^{\prime}$ results obtained by Hutchinson et al. (1980) for 'high' and 'low' liquid limit materials, respectively, was between $7^{\circ}$ and $12^{\circ}$, which was remarkably similar to those obtained by the authors $\left(7^{\circ}-13^{\circ}\right.$; see Fig. 4$)$. The results of residual shear box tests $\left(6 \cdot 5^{\circ}-11 \cdot 5^{\circ}\right)$ made by the authors on cut-plane Gault specimens confirm these data (see Fig. 5). Given the closeness of the results of the authors to those of Hutchinson et al. (1980), if the authors' results are unrepresentative, so alas are those of Hutchinson et al.

The authors propose that the reason why the calculated residual $\phi_{\mathrm{r}}^{\prime}$ value for Slip 2 at Horsehead Point $\left(13^{\circ}\right)$ is larger than the calculated residual values for the three other sections analysed $\left(9 \cdot 3^{\circ}-11 \cdot 7^{\circ}\right)$ is a hinge further west, where first-time movement would be responsible for raising the effective shearing resistance above its residual value on the whole threedimensional extent of the failure surface, including that part underlying Horsehead Point. Hutchinson and Bromhead prefer to draw upon the variability of the shear strength parameters in the Gault, three-dimensional analysis effects, uncertainties about groundwater pressures, and 'rather complicated contacts across the Slip 2 failure surface'. No examples or explanations are given of these "rather complicated contacts"

(a) The authors discuss the variation in the calculated $\phi_{\mathrm{r}}^{\prime}$ value (pp. 616 and 617), and agree that 'some variation in Gault strengths must be anticipated about a given failure surface'. The graph relating plasticity index to $\phi_{\mathrm{r}}^{\prime}$ given in Fig. 13 of the paper (from Skempton et al., 1989) indicates that a plasticity index of about $27 \%$ would be required for a $\phi_{\mathrm{r}}^{\prime}$ value of $13^{\circ}$, which is a very low plasticity index for the Gault as a whole. Only 2 out of 23 plasticity index values reported by the authors were as low as, or lower, than this value; the possibility that Gault having strength properties appropriate to this plasticity index value occurred throughout the Slip 2 failure surface at Horsehead Point seems remote.

(b) The method of Lambe and Whitman (1979) was adopted to take account of the three-dimensional effect in the authors' analysis of Horsehead Point. The uncertainties in using the Lambe and Whitman method in this particular case were acknowledged by the authors (p. 615). It is worth noting that Skempton (1985) concluded that corrections for endeffects were typically $5 \%$ for the landslides studied, which is not large. Hutchinson et al. (1973) found that the calculated two-dimensional $\phi_{\mathrm{r}}^{\prime}$ for a periglacially disturbed marl reduced by $6 \%$ or $13 \%$, when corrected for endeffects, depending upon whether active or at-rest earth pressure conditions were assumed to act on the sides of the slip. For Slip 2 at Horsehead Point, the difference between the calculated and average measured $\phi_{\mathrm{r}}^{\prime}$ values was $27 \%$. Three-dimensional effects would not appear to offer an explanation for a difference of this magnitude.

(c) Groundwater pressure on the slip surface is treated below.

No reference was made to findings by Hutchinson (1995) that the five old landslides (Castle Hill to Danton Pinch) are seated in a common slip-prone zone within Gault Bed XI, because there was no evidence for this at the Warren. On the contrary, and as discussed by the authors at length on pp. 613 and 614 (Pattern of landslide activity), the formation of the Warren was controlled by the dip of the Gault and the successive bouts of landslide activity as the sea level rose in Sub-boreal times. Thus Slip 1 movements occurred as the waves attacked the highplasticity basal Gault at the east end of what is now East Wear Bay, forming large landslides, which were to continue with sea level rise into the west end of the Warren. Slip 2 movements were such that great thicknesses of Gault were cut out, and the Chalk almost rests upon the Folkestone Beds at Warren Halt and Horsehead Point (see Figs 9 and 10 respectively), reducing the Gault to a disturbed, softened and remoulded material with a notably high moisture content (see also the final paragraph of the response to Sir Alan Muir Wood's contribution). In such circumstances, it is not possible to determine from which single Gault Bed the landslide activity sprang, if indeed any single Gault Bed was involved. Work at Castle Hill (see Varley et al., 1996) also failed to demonstrate that a particular horizon within Gault Bed XI was the seat of the landslide activity.

The authors are puzzled that Hutchinson and Bromhead should express disappointment at the state of knowledge of the groundwater pressures on the slip surfaces. Groundwater condi- 
tions are dealt with in detail on p. 609, and the results of a series of piezometer observations are summarised in Table 4. The hydrogeology of the Warren is reported on pp. 614 and 615 , drawing upon the results of the piezometer data, and the groundwater conditions used in the stability analysis are described on p. 616 and are illustrated diagramatically on Fig. 12. Hutchinson and Bromhead will of course appreciate that the authors were conducting a practical site investigation, and that there was a need to define as closely as possible the extent of the failure surfaces in the areas investigated. This required the installation of inclinometers in some $50 \%$ of the boreholes, thus limiting the numbers of piezometers that could be installed. Nevertheless, if the authors were unable to improve significantly upon the earlier state of knowledge, this is a reflection upon the skill of earlier workers in erecting a consistent and appropriate scientific framework, which the present authors were able to flesh out with hard data.

The authors are obliged to Hutchinson and Bromhead for bringing certain minor points to their attention: in particular, they confirm that the units of lateral movement in Fig. 3 are millimetres.

\section{To R. A. Milbourne}

The results of detailed logging of the core from borehole $82 /$ 10 sunk at Warren West End (section 1-1), at the foot of the High Cliff, are described by Mr Milbourne. The upper portion of the core was found to be complete and unaffected by either rotational faulting or landslipping. The lower portion of the core, corresponding to the Lower Gault, differed, exhibiting signs of disturbance. Milbourne regards these signs as being at odds with the interpretation offered by the authors in their Fig. 8. The authors' primary interest was the Warren landslide complex seaward of the High Cliff, but they have to state that they failed to find any significant disturbance in the Lower Gault in borehole 82/10, just as Muir Wood (1955a) failed to observe any significant signs of disturbance in adjacent borehole 48/13. However, they agree that the features described by Milbourne could be an early stage in the formation of a listric fault in the High Cliff erosion sequence.

The authors note the importance attached to the porosity and permeability of the mobile Gault and the significance of the 'Greensand Seam' (the Sulphur Band of the authors), which Milbourne believes facilitated 'the slipping of the wet basal Gault over the indurated top of the Folkestone Beds'. The authors would quite agree with this point, which is expanded in their discussion on 'Pattern of landslide activity', p. 613. See also the discussion on the contribution by Professors Hutchinson and Bromhead. The authors are glad to see that making available the core from borehole 82/10 facilitated Milbourne's research, and thank him for his generous comments.

\section{To P. M. James}

Dr James records the result of a stability analysis made on section W4 of the Warren given in Hutchinson (1969), where the slip surface was within the Gault. No information is given on the pore pressures assumed to act on the failure surface, but a calculated $\phi_{\mathrm{r}}^{\prime}$ value of $8^{\circ}$ was obtained, which compares with calculated values of $9.7^{\circ}$ and $7.7^{\circ}$ for the maximum and minimum pore pressure cases derived by Hutchinson. James' value for the Gault is somewhat lower than the calculated $\phi_{\mathrm{r}}^{\prime}$ values obtained by the authors for the sections they analysed (Table 5), but is within the spread of measured values recorded by both the authors and Hutchinson et al(1980).

James' possible explanations for the difference between his calculated residual shear strength and the authors' values is noted. However, movements involving the chalk (and the chalk rubble) at the Warren were generally so large that their residual shear strengths are highly likely to have been attained.

\section{REFERENCES}

Hutchinson, J. N. (1969). A reconsideration of the coastal landslides at Folkestone Warren, Kent. Géotechnique 19, 6-38.

Hutchinson, J. N. (1987). Some coastal landslides of the southern Isle of Wight. In Wessex and the Isle of Wight (ed. K. E. Barber), pp. 123135. Cambridge: Quaternary Research Association.

Hutchinson, J. N. (1995). Landslide hazard assessment. Keynote paper. Proc. 6th Int. Symp. on Landslides, Christchurch, New Zealand 3, $1805-1841$.

Hutchinson, J. N. (in press) Chalk flows from the coastal cliffs of northwest Europe. In Catastrophic landslides: occurrence, mechanisms and effects. Geological Society of America, Reviews in Engineering Geology.

Hutchinson, J. N., Bromhead, E. N. \& Lupini, J. F. (1980). Additional observations on the landslides at Folkestone Warren. Q. J. Engng Geol. 13 1-31.

James, P. M. (1970). PhD thesis, University of London.

Varley, P. M., Warren, C. D. \& Avgherinos, P. (1996). Castle Hill west landslip. In Engineering geology of the Channel Tunnel (eds C. S. Harris, P. M. Varley and C. D. Warren), pp. 295-309. London: Thomas Telford. 